\title{
Awareness and Willingness to Participate in Community Health Insurance Scheme among Household Heads in Rivers State Nigeria
}

\author{
By Benjamin O Osaro, Ishmael D Jaja \& Tondor C Uzosike
}

Rivers State University

Abstract- Background: Community-Based Health Insurance scheme (CBHI) can guarantee access to quality healthcare services and increase universal health coverage. Enrolments for this scheme in Nigeria is however low. This study sought to assess the awareness and willingness of households in Rivers State to participate in $\mathrm{CBHI}$.

Methodology: This is a cross-sectional descriptive study done in Rivers State, Nigeria. A total of 332 heads of households recruited through multistage sampling and gave written informed consent were interviewed using a pretested interviewer-administered questionnaire. Participants gave information on their socio-demography, awareness and willingness to participate in CBHI and reasons for unwilling to participate. Data were analyzed using IBM SPSS Statistics 22 and results were presented in frequency tables. Chi-square test was done at $P<0.05$.

Keywords: awareness, willingness to participate, community-based health insurance scheme, rivers state.

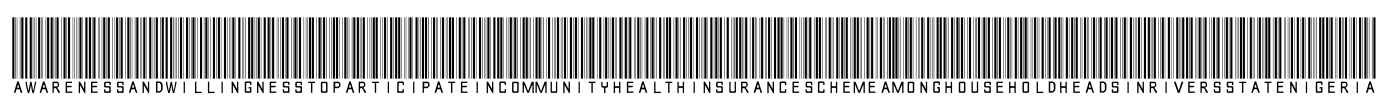

Strictly as per the compliance and regulations of:

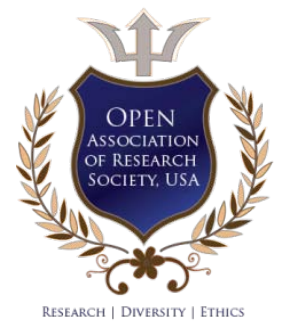

(c) 2021. Benjamin O Osaro, Ishmael D Jaja \& Tondor C Uzosike. This is a research/review paper, distributed under the terms of the Creative Commons Attribution-Noncommercial 3.0 Unported License http://creativecommons.org/licenses/by-nc/3.0/), permitting all non-commercial use, distribution, and reproduction in any medium, provided the original work is properly cited. 


\title{
Awareness and Willingness to Participate in Community Health Insurance Scheme among Household Heads in Rivers State Nigeria
}

\author{
Benjamin O Osaro ${ }^{\alpha}$, Ishmael D Jaja ${ }^{\sigma}$ \& Tondor C Uzosike ${ }^{\rho}$
}

\begin{abstract}
Background: Community-Based Health Insurance scheme $(\mathrm{CBHI})$ can guarantee access to quality healthcare services and increase universal health coverage. Enrolments for this scheme in Nigeria is however low. This study sought to assess the awareness and willingness of households in Rivers State to participate in $\mathrm{CBH}$.

Methodology: This is a cross-sectional descriptive study done in Rivers State, Nigeria. A total of 332 heads of households recruited through multistage sampling and gave written informed consent were interviewed using a pretested interviewer-administered questionnaire. Participants gave information on their socio-demography, awareness and willingness to participate in $\mathrm{CBHI}$ and reasons for unwilling to participate. Data were analyzed using IBM SPSS Statistics 22 and results were presented in frequency tables. Chi-square test was done at $P<0.05$.
\end{abstract}

Results: Only 126 (38.0\%) participants had the awareness of $\mathrm{CBHI}$. Those willing to participate or enroll other family members were $272(82.5 \%)$ and $174(63.5 \%)$ respectively with 157 (57.3\%) willing to pay a premium of $\mathrm{N} 2,000.00$ or less either once or twice a year or monthly. Associated with the willingness to participate in $\mathrm{CBHI}$ were awareness $(P=0.037)$, the number of living children $(P=0.025)$, partner's level of education $(P=0.041)$ and experience of catastrophic health expenditure $(P<00001)$. Financial constraints and lack of trust were the most common reasons for unwillingness to participate in $\mathrm{CBHI}$.

Conclusion: The awareness of $\mathrm{CBHI}$ in Rivers State is low but the willingness to participate is high. Community engagement to increase awareness of $\mathrm{CBH}$ should be strengthened.

Keywords: awareness, willingness to participate, community-based health insurance scheme, rivers state.

\section{INTRODUCTION}

A Ithough life expectancy at birth has improved globally, disparity still exists between the highincome countries on one side and the low- and medium-income countries (LMIC) on the other side. These improvements in life expectancy at birth has been attributed inter alia to improvements in standard of living, health care services delivery and its access. ${ }^{1}$ In sub-Saharan Africa, life expectancy at birth is currently at 59.5years. ${ }^{1}$ This however, is below that in parts of the

Corresponding Author a: Department of Community Medicine, Rivers State University, Port Harcourt, Nigeria.

e-mails: benjamin.osaro@ust.edu.ng,boosaro@hotmail.com

Author $\sigma \rho$ : Department of Community Medicine, Rivers State University, Port Harcourt, Nigeria. developed and high-income countries of the world where life expectancy is over 70.5years. ${ }^{1}$ Recent discourse to improve inequalities in health among nations and within countries has centered on increasing universal health coverage in order to improve access to and utilization of high quality and efficacious healthcare services. ${ }^{2,3}$ Health care cost for majority of people in developing countries like Nigeria has relied on out-ofpocket (OOP) expenditures. ${ }^{4}$ This is occasionally catastrophic and accounts for over $70 \%$ of the total family's income, an expenditure far above the recommended $30 \% .^{5-7}$ Most countries of the world have introduced social health insurance programs aimed at ensuring access to healthcare when needed without unduly exposing individuals and families to financial hardship or impoverishment. These forms of insurance hinge on the pooling of funds and resources from enrollees and sharing of financial risk in the event of illnesses especially of catastrophic nature. ${ }^{8-{ }^{10}}$ In Nigeria the National Social Health Insurance scheme was implemented in 2005 six years after the enactment of its enabling law (NHIS Act 35 of 1999). ${ }^{11-13}$ This scheme made provision for the enrolment of the different subpopulations in the country through organized formal sector insurance schemes like the Public Sector and Organized Private Sector Employees and Tertiary Institutions Health Insurance Scheme (TSHIP) as well as the informal sector health insurance schemes like the Urban Self-Employed Individuals and Rural Community dwellers insurance schemes amongst others.

In Nigeria and other countries in Africa, the informal sector constitutes the majority population. ${ }^{14}$ These reside in rural settings where healthcare service is of low quality and access also poor with attendant adverse consequences on their health, dignity and ability to earn income. ${ }^{6,15}$ Health insurance systems that provides financial protection from catastrophic healthcare needs of this sector is community-based health insurance: a system of pooling of funds from individuals and families in the community on the based on solidarity to provides healthcare services to members of the community. ${ }^{8,16}$ Enrolment in Community Health Insurance is voluntary however, to prevent adverse selection and decapitation of the insurance scheme, enrolment is in groups of at least 500 persons who are residents in the community and who may/or not share a 
similar occupation. Premium is usually a flat sum, not risk-related and payment is also flexible on a monthly or seasonal basis to encourage en masse enrolment. ${ }^{7,13}$ Payment of premium guarantees enrollees and/or their dependents access to a minimum benefit package which covers their basic health needs for treatment of malaria, typhoid fever, tuberculosis, diarrhea, etc. ${ }^{10,17}$

Although the formal sector insurance scheme has made significant improvement in its enrolment since inception, the informal sector rural community health insurance scheme targeting individuals and families in rural settings, trails far behind with an enrolment rate of $2 \%$ as of $2014 .{ }^{3}$ Studies have reported an abysmally low level of awareness of CBHIS of 3.9\% and enrolment of 2.9\% among artisans in Abakiliki Nigeriadespite their effectiveness in ensuring financial risk protection from catastrophic health expenditures to individuals and families in rural communities. ${ }^{11-18}$ Furthermore, the willingness to participate in CBHIS ranged from $69.3 \%$ 97.0\% among different populations in Nigeria ${ }^{6,8,9,11,19}$ while the willingness to a pay premium of between $\$ 400$ - A5000 per annum per person for any form of voluntary health insurance also varies among communities, ranging from 28\% in Kwara State to $82.0 \%$ in Kaduna State, Nigeria. ${ }^{2,5-7,9,11},{ }^{17}$ Participation is largely determined by such factors like age and sex of household head, size of household, previous experience of borrowing to fund healthcare, level of education and income. ${ }^{5,8,9}$, Very few $\mathrm{CBH}$ schemes are in operation in Nigeria despite the legal framework provided by the NHIS Act $99 .{ }^{17}$ The willingness to participate in $\mathrm{CBH}$ schemes in communities in Rivers State Nigeria is yet to be assessed therefore this study seeks to determine knowledge, willingness and barriers to participation in community health insurance schemes by individuals and families in communities in Rivers State.

\section{Methods}

\section{a) Study setting}

This study was carried out in Rivers State, Nigeria located in the Niger Delta region of Nigeria. Rivers State is comprised of 23 Local Government Areas (LGAs) grouped into three Senatorial Districts. Each of the LGA is delineated into ten or more political wards. Twenty of them are rural. Healthcare services in each LGA are provided at the various Health posts, Chemist/Patent Medicine Vendors, Primary Healthcare Centres, privately owned health clinics and a General Hospital which doubles as a referral centre. There are two tertiary level healthcare centres in Rivers State which receive referrals from the peripheral hospitals.

\section{b) Study design and sampling}

This study was a cross sectional descriptive study using head of households aged 18 years and above, and resident in Rivers State, Nigeria. The minimum sample size was determined as 327 using the
Leslie Fischer's formula ${ }^{11} n=Z^{2} p q / d^{2}$; where $n=$ minimum sample size; $Z=$ Level of statistical significance $=95 \%$ (1.96); $P=$ the estimated proportion of those willing to participate in CBHIS $=69.3 \%{ }^{9}=$ 0.693; $q=1-p=0.307 ; d=$ Precision/error tolerated $(5 \%)=0.05$. However, this was increased to 360 to accommodate for non-response of $10 \%$.

A multistage sampling method was adopted in recruiting participants for this study. One LGA was selected in each of the three Senatorial Districts in the State. In each selected LGA, ten political wards were selected and finally 12 heads of households who are 18 years and above from each political ward.

\section{c) Data collection}

Data were collected from participants who gave consent using a pretested interviewer-administer questionnaire. Participants provided information on socio-demography, family's illness experiences and health expenditure, awareness and knowledge on $\mathrm{CBHIS}$, willingness to participate in CBHIS, the amount they are willing to pay as premium and reasons for unwillingness to participate in CBHIS.

\section{d) Data analysis}

The collected data was analyzed using IBM SPSS Statistics 22 and results presented in frequency tables. The primary outcome variable: Willingness to participate in CBHIS, was assessed as the proportion of participants who were willing to enroll for CBHIS. However how much participants were willing to pay as premium was determined using the contingency valuation method where the amount was bided from the highest amount of $\$ 5,000.00$ to the lowest amount respondent is willing to pay. ${ }^{5}$ Secondary outcome variable: awareness of CBHIS' was determined as the proportion of respondents who have heard about $\mathrm{CBHIS}$, knowledge of CBHIS, was determined with a 10point knowledge score. The knowledge of CBHIS by participants was categorized as poor (score 1 - 4), good (score $5-6$ ) or very good (score $7-10$ ). The financial burden of respondents was assessed as catastrophic if a household expenditure on health involves spending all their monthly income, savings, donations, borrowings and/or sales of assets. ${ }^{20}$

Chi-square $\left(X^{2}\right)$ test was done to determine the association of willingness to participate in CBHIS on one hand and socioeconomic variables and knowledge of $\mathrm{CBHIS}$ on the other hand. The level of statistical significance was set at $P<0.05$.

\section{ili. Ethical Approval}

The Rivers State Health Research Ethics Committee approved this study. Participants were fully informed of the objectives of the study, assured of the confidentiality of their responses and that participation is voluntary. Written informed consent were obtained from participants before data collection. 


\section{Result}

A total of 332 head of households participated in this study out of 360 selected. Majority of the participants were $35-44$ years of age $(n=112 ; 33.7 \%)$ and employed by Government ( $n=79 ; 23.8 \%)$. Nearly three-quarter of them are married $(n=242 ; 72.9 \%)$ with more than half attaining tertiary education $(\mathrm{n}=171$; 51.5\%) Table 1.

Table 1: Socio-demographic characteristics of respondents

\begin{tabular}{|c|c|c|}
\hline Variables & Frequency $(n=332)$ & Percent \\
\hline \multicolumn{3}{|l|}{ Age (years) } \\
\hline$<25$ & 19 & 5.7 \\
\hline $25-34$ & 76 & 22.9 \\
\hline $35-44$ & 112 & 33.7 \\
\hline $45-54$ & 66 & 19.9 \\
\hline $55-64$ & 26 & 7.9 \\
\hline$>64$ & 33 & 9.9 \\
\hline Mean (SD) & $40.45(11.08)$ & \\
\hline \multicolumn{3}{|l|}{ Sex } \\
\hline Male & 178 & 53.6 \\
\hline Female & 154 & 46.4 \\
\hline \multicolumn{3}{|l|}{ Marital status } \\
\hline Married & 242 & 72.9 \\
\hline Separated/divorced & 9 & 2.7 \\
\hline Widow & 11 & 3.3 \\
\hline Single & 70 & 21.1 \\
\hline \multicolumn{3}{|l|}{ Level of education } \\
\hline Primary & 23 & 6.9 \\
\hline Secondary & 132 & 39.8 \\
\hline Tertiary & 171 & 51.5 \\
\hline None & 6 & 1.8 \\
\hline \multicolumn{3}{|c|}{ Partner's level of education* } \\
\hline Primary & 29 & 11.2 \\
\hline Secondary & 108 & 41.7 \\
\hline Tertiary & 115 & 44.4 \\
\hline None & 7 & 2.7 \\
\hline \multicolumn{3}{|l|}{ Occupation } \\
\hline Farming & 30 & 9.0 \\
\hline Fishing & 22 & 6.6 \\
\hline Trading & 67 & 20.2 \\
\hline Government employee & 79 & 23.8 \\
\hline Private sector employee & 70 & 21.1 \\
\hline Unemployed & 64 & 19.3 \\
\hline \multicolumn{3}{|l|}{ Partner's occupation } \\
\hline Farming & 40 & 12.0 \\
\hline Fishing & 10 & 3.0 \\
\hline Trading & 68 & 20.5 \\
\hline Government employee & 47 & 14.2 \\
\hline Private sector employee & 53 & 16.0 \\
\hline Unemployed & 114 & 34.3 \\
\hline
\end{tabular}

*missing values $(n=259)$

Nearly two-thirds of the participants earn less than the minimum wage of $\$ 30,000$ monthly $(n=199$; $59.9 \%$ ) with 128 of them (38.6\%) having $3-4$ children.

(Table 2) 
Table 2: Income and family size distribution of respondents

\begin{tabular}{lcc}
\hline Variables & Frequency $(\mathrm{n}=332)$ & Percent \\
\hline Average monthly Income $(\mathrm{A}))^{*}$ & 199 & \\
$<30,000$ & 60 & 59.9 \\
$30,000-50,000$ & 19 & 18.2 \\
$50,001-70,000$ & 18 & 5.7 \\
$70,001-90,000$ & 13 & 5.4 \\
$90,001-110,000$ & 11 & 3.9 \\
$110,001-130,000$ & 6 & 3.3 \\
$130,001-150,000$ & 6 & 1.8 \\
$>150,000$ & & 1.8 \\
No of living children & 2 & \\
0 & 93 & 0.6 \\
$1-2$ & 128 & 28.0 \\
$3-4$ & 109 & 38.6 \\
$\geq 5$ & $3.14(1.53)$ & 32.8 \\
Mean (SD) & & \\
No of male children & 25 & 7.5 \\
0 & 209 & 63.0 \\
$1-2$ & 35 & 10.5 \\
$3-4$ & 63 & 19.0 \\
$\geq 5$ & $1.57(0.93)$ & \\
Mean (SD) & & 12.0 \\
No of female children & 40 & 54.8 \\
0 & 182 & 12.7 \\
$1-2$ & 42 & 20.5 \\
$3-4$ & 68 & \\
$\geq 5$ & $1.59(1.158)$ & \\
Mean (SD) & & \\
\hline
\end{tabular}

*skewed data (modal income $=$ N20,000)

Two hundred (60.2\%) of the participants had 1 -

$121 ; 42.0 \%)$ attend Government hospitals/dispensaries 2 members of the family experiencing illness episodes within the last 12 months. Among these, majority ( $\mathrm{n}=$ for treatment. Only 32 (9.6\%) participants are enrolled on any health insurance scheme. (Table 3 )

Table 3: Family illness experience and enrolment on Insurance schemes

\begin{tabular}{lcc}
\hline \multicolumn{1}{c}{ Variables } & $\begin{array}{c}\text { Frequency } \\
(\mathrm{n}=332)\end{array}$ & Percent \\
\hline Family members sick in the last 12 months & & \\
0 & 44 & 13.3 \\
$1-2$ & 200 & 60.2 \\
$3-4$ & 67 & 20.2 \\
$\geq 5$ & 21 & 6.3 \\
Mean (SD) & $2.09(1.44)$ & \\
Where do you go for Rx when someone is sick $(n=288) *$ & 5 & \\
Prayer house & 118 & 41.8 \\
Chemist & 7 & 2.4 \\
Home remedies & 30 & 10.4 \\
Private clinics & 121 & 42.0 \\
Government hospitals/Dispensaries & 7 & 2.4 \\
Others & & \\
Enrolment in Insurance schemes & 32 & 9.6 \\
Yes & 300 & 90.4 \\
No & & 34.3 \\
Type of Insurance schemes enrolled on $(n=32) * *$ & 11 & \\
Public sector and organized private sector employee Social insurance & & \\
scheme & & \\
\hline
\end{tabular}




\begin{tabular}{lcc}
\hline Tertiary Institutions Social Health Insurance Scheme & 2 & 6.3 \\
Voluntary contribution Social Insurance Scheme & 1 & 3.1 \\
Rural Community Social Health Insurance Scheme & 14 & 43.8 \\
Children Under-five Social Health Insurance Scheme & 4 & 12.5 \\
\hline
\end{tabular}

* Participants who had illness experience ** Participants enrolled on an Insurance scheme

Most $(n=164 ; 56.9 \%)$ of the participants spent defrayed by insurance scheme whereas in 178(61.8\%), it up to $\mathrm{A10,000}$ on the treatment of illnesses in the family. was done with some of the family savings. Less than In 16 participants (5.6\%), payment for treatment was 20\% had catastrophic expenditures (Table 4).

Table 4: Health expenditure and source of funding among participants who had illness experience

\begin{tabular}{lcc}
\multicolumn{1}{c}{ Variables } & $\begin{array}{c}\text { Frequency } \\
(\mathrm{n}=\mathbf{2 8 8})\end{array}$ & Percent \\
\hline Amount spent in last 12 months (A) & 164 & 56.9 \\
$1-10,000$ & 46 & 16.0 \\
$10,001-20,000$ & 20 & 6.9 \\
$20,001-30,000$ & 9 & 3.1 \\
$30,001-40,000$ & 15 & 5.2 \\
$40,001-50,000$ & 18 & 6.3 \\
$50,001-100,000$ & 16 & 5.6 \\
$>100,000$ & & 5.9 \\
Mode of payment for treatment* & 17 & 62.8 \\
paid for Rx with my Insurance Scheme & 181 & 8.3 \\
Paid for Rx with some of the family's savings & 24 & 17.0 \\
Paid with all the family savings** & 49 & 18.4 \\
Borrowed money to pay for treatment** & 53 & 9.4 \\
Sold family's property to pay for treatment** & 27 & \\
Paid from donations from friends and other family support** & & \\
\hline
\end{tabular}

Modal expenditure $=$ A10,000.00; * multiple options; ** Catastrophic expenditure

Only $126(38.0 \%)$ of the respondents had the awareness of $\mathrm{CBHI}$. Among these about half $(\mathrm{n}=68$; $54.0 \%$ ) had very good knowledge of $\mathrm{CBHIS}$ and 38
(30.2\%) had good knowledge. The commonest source of information on CBHIS were churches ( $n=31 ; 24.6 \%$ ) Table 5.

Table 5: Awareness and sources of information on CBHIS

\begin{tabular}{lcc}
\hline \multicolumn{1}{c}{ Variables } & $\begin{array}{c}\text { Frequency } \\
(\mathrm{n}=332)\end{array}$ & Percent \\
\hline Awareness of CBHI & 126 & 38.0 \\
Yes & 206 & 62.0 \\
No & & \\
Knowledge of CBHIS* & 68 & 54.0 \\
Very good & 38 & 30.2 \\
Good & 20 & 15.8 \\
Poor & & \\
Sources of information on & CBHI** & \\
Church & 31 & 24.6 \\
Friends & 23 & 18.3 \\
Hospitals/Clinics & 19 & 15.1 \\
Community leaders & 17 & 13.5 \\
Radio/TV & 10 & 7.9 \\
Club meetings & 4 & 3.2 \\
NGOs & 2 & 1.6 \\
\hline
\end{tabular}

* Participants who have awareness of $\mathrm{CBHI}$ ** multiple options

Participants who were willing to enroll for $\mathrm{CBHIS}$ were 274 (82.5\%). Among these 174 (63.5\%) participants were willing to enroll other members of the family. Treatment of mild medical illnesses that do not require hospital admission was the most common service desired ( $n=198 ; 72.3 \%)$. A total of 157 (57.3\%) participants were willing to pay a premium of $\$ 2000$ or less while $87(31.8 \%)$ participants were willing to pay premium once a year (Table 6). 
Table 6: Willingness of participants to enroll for $\mathrm{CBHI}$ schemes

\begin{tabular}{|c|c|c|}
\hline Variables & $\begin{array}{l}\text { Frequency } \\
(\mathrm{n}=332)\end{array}$ & Percent \\
\hline \multicolumn{3}{|l|}{ Willingness to enroll in a $\mathrm{CBHI}$} \\
\hline Yes & 274 & 82.5 \\
\hline No & 58 & 17.5 \\
\hline \multicolumn{3}{|l|}{ Willingness to enroll every member of the family* } \\
\hline Yes & 174 & 63.5 \\
\hline No & 100 & 36.5 \\
\hline \multicolumn{3}{|l|}{ Desired services when enrolled*\$ } \\
\hline $\begin{array}{l}\text { Treatment of mild medical illnesses that do not require hospital } \\
\text { admission }\end{array}$ & 198 & 72.3 \\
\hline $\begin{array}{l}\text { Treatment of serious medical conditions that require hospital } \\
\text { admission }\end{array}$ & 184 & 67.2 \\
\hline Surgeries & 130 & 47.4 \\
\hline Delivery services & 101 & 36.9 \\
\hline Immunization & 106 & 38.7 \\
\hline Family planning & 99 & 36.1 \\
\hline Antenatal care & 97 & 35.4 \\
\hline \multicolumn{3}{|l|}{ Amount participants are willing to pay $(\mathrm{A}))^{*}$} \\
\hline$\leq 1000$ & 78 & 28.5 \\
\hline $1001-2000$ & 79 & 28.8 \\
\hline $2001-3000$ & 49 & 17.9 \\
\hline $3001-4000$ & 30 & 10.9 \\
\hline $4001-5000$ & 35 & 12.8 \\
\hline$>5000$ & 3 & 1.1 \\
\hline Range & \multicolumn{2}{|c|}{$A 100-A 20,000$} \\
\hline Mode** & \multirow{2}{*}{\multicolumn{2}{|c|}{ A 2000}} \\
\hline Preferred method of payment* & & \\
\hline Weekly & 8 & 2.9 \\
\hline Monthly & 62 & 22.6 \\
\hline Quarterly & 38 & 13.9 \\
\hline Twice a year & 63 & 23.0 \\
\hline Once a year & 87 & 31.8 \\
\hline Missing & 16 & 5.8 \\
\hline
\end{tabular}

* Participants willing to enroll for CBHIS; **Skewed data; \$ multiple options

Table 7 shows that there is a statistically education $(P=0.04)$, as well as the experience of significant association between willingness to enroll for $\mathrm{CBHI}$ scheme and awareness of $\mathrm{CBHI}(P=0.037)$, the number of living children $(P=0.025)$, partner's level of catastrophic expenditures $(P<0.0001)$ but not with average monthly income $(P=0.375)$.

Table 7: Test of Association between willingness to enroll for $\mathrm{CBHI}$ scheme and outcome variables

\begin{tabular}{|c|c|c|c|}
\hline \multirow[t]{2}{*}{ Variables } & \multicolumn{2}{|c|}{$\begin{array}{l}\text { Willingness to enroll } \\
\text { for CBHI scheme }\end{array}$} & \multirow{2}{*}{$\begin{array}{c}X^{2} \\
(P \text {-value })\end{array}$} \\
\hline & Yes & No & \\
\hline \multicolumn{4}{|c|}{ Awareness of $\mathrm{CBHI}$} \\
\hline Yes & 111 & 15 & $4.349(0.037)^{\star}$ \\
\hline No & 163 & 43 & \\
\hline \multicolumn{4}{|c|}{ Knowledge of $\mathrm{CBHI}$} \\
\hline Very good & 62 & 6 & 1.922 \\
\hline Good & 33 & 5 & $(0.382)$ \\
\hline Poor & 16 & 4 & \\
\hline \multicolumn{4}{|c|}{ No of living children } \\
\hline 0 & 2 & 0 & \\
\hline $1-2$ & 80 & 13 & \\
\hline $3-4$ & 112 & 16 & 9.712 \\
\hline
\end{tabular}




\begin{tabular}{|c|c|c|c|}
\hline$\geq 5$ & 80 & 29 & $(0.025)^{\star}$ \\
\hline \multicolumn{4}{|l|}{ Average monthly income (A) } \\
\hline$<30000$ & 162 & 37 & \\
\hline $30000-50000$ & 48 & 12 & \\
\hline $50001-70000$ & 16 & 3 & \\
\hline $70001-90000$ & 13 & 5 & \\
\hline $90001-110000$ & 12 & 1 & 7.535 \\
\hline $110001-130000$ & 11 & 0 & $(0.375)$ \\
\hline $130001-150000$ & 6 & 0 & \\
\hline$>150000$ & 6 & 0 & \\
\hline \multicolumn{4}{|l|}{ Level of education } \\
\hline Primary & 19 & 4 & \\
\hline Secondary & 110 & 22 & \\
\hline Tertiary & 141 & 30 & 1.107 \\
\hline None & 4 & 2 & $(0.695)$ \\
\hline \multicolumn{4}{|l|}{ Partner's level of education } \\
\hline Primary & 25 & 4 & \\
\hline Secondary & 90 & 18 & \\
\hline Tertiary & 105 & 10 & 8.362 \\
\hline None & 4 & 3 & $(0.041)^{*}$ \\
\hline \multicolumn{4}{|l|}{ Occupation } \\
\hline Farming & 24 & 6 & \\
\hline Fishing & 19 & 3 & \\
\hline Trading & 59 & 8 & 5.291 \\
\hline Government employee & 62 & 17 & $(0.381)$ \\
\hline Private sector employee & 61 & 9 & \\
\hline Unemployed & 49 & 15 & \\
\hline \multicolumn{4}{|l|}{ Occupation of partner } \\
\hline Farming & 30 & 10 & \\
\hline Fishing & 8 & 2 & \\
\hline Trading & 59 & 9 & \\
\hline Government employee & 39 & 8 & \\
\hline Private sector employee & 49 & 4 & 7.662 \\
\hline Unemployed & 89 & 25 & $(0.176)$ \\
\hline \multicolumn{4}{|l|}{ Age (years) } \\
\hline$<25$ & 16 & 3 & \\
\hline $25-34$ & 64 & 12 & 4.639 \\
\hline $35-44$ & 93 & 19 & $(0.461)$ \\
\hline $45-54$ & 49 & 17 & \\
\hline $55-64$ & 23 & 3 & \\
\hline$>64$ & 29 & 4 & \\
\hline \multicolumn{4}{|l|}{ Experience of catastrophic expenditure } \\
\hline Paid with all the family savings & 19 & 5 & 74.971 \\
\hline Borrowed money to pay for Rx & 43 & 6 & $(<0.00001)^{*}$ \\
\hline Sold family's property to pay for $R x$ & 7 & 46 & \\
\hline $\begin{array}{l}\text { Paid from donations from friends and other family } \\
\text { support }\end{array}$ & 23 & 4 & \\
\hline
\end{tabular}

The commoner reasons participants were not willing to participate in a $\mathrm{CBH}$ scheme were 'lack of regular income to pay or renew premium' ( $\mathrm{n}=17$; am sick without payment' ( $\mathrm{n}=16 ; 27.6 \%)$. 'Hospital is far away' was the least common reason for not willing to participate CBHI scheme $(n=1 ; 1.7 \%)$ Table 8. 29.3\%) and 'I don't believe that I will be treated when I

Table 8: Reason for not willing to participate in $\mathrm{CBHI}$ scheme

\begin{tabular}{lcc}
\hline \multicolumn{1}{c}{ Reason for not willing to participate in CBHI scheme } & $\begin{array}{c}\text { Frequency } \\
(\mathrm{n}=\mathbf{5 8})\end{array}$ & Percent \\
\hline Lack of regular income to pay or renew premium & 17 & 29.3 \\
I don't believe that I will be treated when I am sick without payment & 16 & 27.6 \\
Not interested in Insurance & 9 & 15.5 \\
\hline
\end{tabular}


I may not meet up the requirements for enrolment like enrolling 6 everybody in my family.

Services rendered are of poor quality

I will lose my premium if I don't fall sick

No support from wealthy people in the community

Timing of payment of premium may not be conducive

$\begin{array}{ll}5 & 8.6 \\ 5 & 8.6 \\ 5 & 8.6 \\ 4 & 6.9\end{array}$

My family is too large to pay a premium for everybody Not aware of the scheme

My culture forbids saving money for illness

Hospital is far away
8.6

6.9

5.2

5.2

1.7

1.7

\section{Discussion}

One mechanism for financing of healthcare services in low- and medium-income countries of the world, where funding of healthcare services is poor, is Community-based health insurance. In Nigeria this model has been integrated into the National Social Health Insurance Schemes in order to improve access to healthcare services for the informal sector and the poor. ${ }^{6,15}$ This study is aimed at determining awareness of $\mathrm{CBHI}$ and the willingness of head of households in Rivers State Nigeria to participate in it. The awareness of $\mathrm{CBHI}$ is low in Rivers State Nigeria. In this study about one-third (38\%) of respondents have heard about $\mathrm{CBH}$. Studies previously conducted in some parts of Nigeria also show that awareness of $\mathrm{CBHI}$ is still low. For instance, among artisans in Abakiliki, Nigeria only 3.9\% of them are aware of $\mathrm{CBHI} .{ }^{11}$ Residents in a capital city of Nigerian who have the awareness of $\mathrm{CBHI}$ were only $13 \%{ }^{6}$, while in a suburb in Lagos, $19.8 \%$ of residents were aware of $\mathrm{CBHI} .{ }^{21}$ Furthermore, a similar finding was reported in a health District in Douala Cameroun, where $25.6 \%$ of informal workers were aware of the existence of $\mathrm{CBH}$ schemes. ${ }^{22}$ The level of awareness of $\mathrm{CBHI}$ scheme has also being reportedly high in other populations. For instance $52.2 \%$ and $91 \%$ of participants, in studies done in North-western Nigeria and in Tanzania respectively, have the awareness of $\mathrm{CBHI} .{ }^{9}, 18$ Awareness of $\mathrm{CBHI}$ in most developing countries is low probably because of poor mass media and community sensitization campaigns promoting health insurance schemes particularly in rural areas. ${ }^{21,22}$ The commonest sources of information on health insurance in this study were churches (24.6\%) and friends (18.3\%). Other studies reported common sources of information on $\mathrm{CBHI}$ as radio, friends, community leaders and television among household heads in FCT Nigeria, ${ }^{6,18}$ whereas among residents in a Lagos suburb it was community sensitization and community members. ${ }^{21}$ This study found that among respondents who have awareness of $\mathrm{CBHI}$, more than four-fifth (84.2\%) have at least a fair knowledge of $\mathrm{CBHI}$. Good knowledge of $\mathrm{CBHI}$ was similarly high (71\%) among respondents in the North Central Zone of Nigeria but low (37\%) among residents in a suburb of Lagos. ${ }^{21,23}$ Enrolment for $\mathrm{CBHI}$ is low among households in Nigeria and elsewhere. Only $9.6 \%$ of households in this study were currently enrolled in a health insurance program. The majority of them (43.0\%) enrolled in rural $\mathrm{CBHI}$ schemes like the Obio Cottage health insurance in Port Harcourt and Community Health Insurance Scheme in Bonny. Other studies reported lower enrolment into $\mathrm{CBHI}$ schemes. For instance, $\mathrm{CBH}$ enrollees were $6.7 \%$ in FCT Nigeria, $4.5 \%$ in a suburb in Lagos Nigeria, 2.9\% among artisans in Abakiliki and 1.2\% among informal sector workers in Douala, Cameroun. 6,11,21,22

Although enrolment for $\mathrm{CBH}$ scheme is low in this study, over four-fifths (82.5\%) of household heads have the willingness to enroll themselves in $\mathrm{CBHI}$ scheme while approximately two-thirds (63.5\%) were willing to enroll members of their households. Related studies have similarly reported a very high willingness of household heads to enroll in a $\mathrm{CBH}$ scheme. In these studies more than three - quarters of the respondents were willing to enroll for $\mathrm{CBH}$ schemes in Nigeria ${ }^{6,23}$ and elsewhere ${ }^{2,8,22}$ whereas in others, approximately twothirds of heads of households were willing to enroll in $\mathrm{CBHI}$ schemes. ${ }^{7,21}$ When out of pocket expenditure on health is catastrophic, individuals and families become impoverished. This further increases the risk of poor health as well as denial of access to quality healthcare services. ${ }^{5}$ Income and educational level of enrollees have been reported to influence their willingness to enroll for an insurance scheme. ${ }^{2,9}$ The poor who have experienced catastrophic health expenditure because of their low ability to pay for health services at points of care, better appreciate the benefits of a community health insurance scheme and are more willing to enroll in $\mathrm{CBHI}$ schemes. ${ }^{8}$ This study found no statistically significant association between willingness to participate in CBHIS and income levels of respondents $(P=0.375)$ or the level of education of respondents $(P=0.7)$ as reported in another study. ${ }^{9}$ However the association between respondents' willingness to participate in $\mathrm{CBHI}$ and having a catastrophic health expenditure $(P<$ 0.00001), number of living children $(P=0.025)$, 
awareness of $\mathrm{CBH}$ by respondents $(P=0.037)$ and level of education of their partners $(P=0.041)$ were statistically significant. Kibret et al similarly reported that households who borrowed to pay for healthcare services were 2-7 times more willing to enroll for $\mathrm{CBHI}{ }^{8}$ Sixty percent of heads of households in this study earn less than $130,000.00$ monthly, the minimum wage in Nigeria; more than half (57.0\%) had spent on the average $10,000.00$ on healthcare expenses in the last 12 months and only $6.0 \%$ paid for healthcare services through an insurance scheme. Furthermore, the knowledge of the benefits of health insurance programs by individuals in the community is key to their decisions to enroll in $\mathrm{CBHI}$ schemes. Approximately half (52.0\%) of the respondents and $44.0 \%$ of their partners have tertiary level education. Individuals who have had catastrophic health expenditure as well as those with more education can appraise the risk-benefit packages of a health insurance scheme better than the less educated and thus more willing to participate. ${ }^{5,11}$ Such catastrophic experiences coupled with the high level awareness of $\mathrm{CBHI}$ of respondents and of education of their partners who possibly play roles in decisions on enrolment may likely account for the high level of willingness to enroll for $\mathrm{CBH}$ schemes by respondents in this study irrespective of their incomes. ${ }^{2}$

Most of the respondents were willing to pay a premium of $\# 2,000.00$ per head per annum (range 100 - $\$ 20,000.00)$ for treatment of mild medical conditions on an outpatient basis as well as serious conditions requiring hospitalization. This finding is comparable to the annual premium reported in other studies as prepayment for healthcare services which may or not include surgery and other treatments requiring hospitalization. ${ }^{4,11},{ }^{17}$ In terms of flexibility of payment of premium, majority of the respondents in this study preferred once a year payment followed by twice a year or monthly. In another study however, the monthly payment pattern was the most preferred method among informal sector workers. ${ }^{22}$ Although this study did not assess the factors that determine how much enrollees are willing to pay, other studies found age and level of education of household head, monthly income, farm size or wealth status of the family, household size as determinants of amount enrollees were willing to pay. These factors may be due to the awareness of and actual experience of catastrophic expenditures following illness events within the family. ${ }^{2,17,23}$

Among the reasons respondents in this study gave for their unwillingness to enroll for $\mathrm{CBHI}$, financial constraints (lack of regular income to pay and renew premium) and distrust for the insurance scheme (I don't believe that I will be treated when I am sick without payment) were the commonest. In similar studies, lack of awareness, trust, interest, altruism (an attitude of viewing premium as a contribution to the success of
$\mathrm{CBHI}$ ) and the solidarity principle (an attitude of 'somebody else will use up my premium if I don't use it'), etc have also been reported as 'demand side' barriers to enrolment for insurance schemes. 6,11,21

\section{Conclusion}

Although the awareness of Community-Based Health Insurance is low in Rivers State, knowledge of $\mathrm{CBHI}$ is high among those with awareness. Enrolment is also low however, majority of the people have the willingness to enroll themselves and members of their family.

A statistically significant association was found between willingness to enroll for CBHIS and awareness of $\mathrm{CBHIS}$, number of living children, level of education of partner and the experience of catastrophic health expenditure. Community engagement programs to increase the awareness of CBHIS should be implemented to increase enrolment and improve access to high-quality healthcare services.

\section{Vil. Limitation of the Study}

Information analyzed were obtained from the responses of participants. These responses are dependent on their memory recall which may introduce information bias.

Conflict of Interest

$\mathrm{Nil}$

Financial support

This research was funded entirely by the researchers.

\section{References Références Referencias}

1. United Nations, Department of Economic and Social Affairs, Population Division (2017). World Mortality Report 2015 - Highlights (ST/ESA/SER.A/382).

2. Minyihun $A$, Gebregziabher $M G$ and Gelaw $Y A$. Willingness to pay for community-based health insurance and associated factors among rural households of Bugna District, Northeast Ethiopia. BMC Res Notes. 2019; 12:55

3. Christian Aid 2015. A Review of Community-Based Health Insurance Schemes: Lessons from Nigeria and Ghana. Abuja, Nigeria: Christian Aid.

4. Onwujekwe et al.: Investigating determinants of out of-pocket spending and strategies for coping with payments for healthcare in southeast Nigeria. BMC Health Services Research 2010; 10:67.

5. Ogundeji YK, Akomolafe B, Ohiri K, Butawa NN Factors influencing willingness and ability to pay for social health insurance in Nigeria. PLOS ONE. 2019; 14(8): e0220558. https://doi.org/10.1371/journal. pone.0220558

6. Adedeji AS, Doyin A, Kayode OG, and Ayodele AA. Knowledge, Practice, and Willingness to Participate in Community Health Insurance Scheme among 
Households in Nigerian Capital City. Willingness to Participate in Community Health Insurance Scheme among Households in Nigerian Capital City," Sudan Journal of Medical Sciences. 2017; 12 (1): 9-18. DOI 10.18502/sjms.v12i1.854.

7. Shafie AA, Hassali MA. Willingness to pay for voluntary community-based health insurance: Findings from an exploratory study in the state of Penang, Malaysia. Social Science \& Medicine. 2013; 96: 272-276.

8. Kibret GD, Leshargie CT, Wagnew F and Alebel A. Willingness to join community based health insurance and its determinants in East Gojjam zone, Northwest Ethiopia. BMC Res Notes. 2019; 12:31.

9. Abdulganiyu G, Muhammad K, Ibrahim U, Suleiman $\mathrm{HH}$, Lawal BK. Awareness and Willingness to Pay for Community Based Health Insurance Scheme in North-Western Nigeria. Journal of Pharmaceutical and Health Sciences. 2018;6(2): 139-147.

10. Doetinchem O, Carrin G, Evans D. Thinking of introducing social health insurance? Ten questions. World Health Report (2010) Background Paper, No 26.

11. Azuogu BN, Eze NC. Awareness and Willingness to Participate in Community Based Health Insurance among Artisans in Abakaliki, Southeast Nigeria. Asian Journal of Research in Medical and Pharmaceutical Sciences. 2018; 4(3): 1-8. Article no.AJRIMPS.42839

12. Odeyemi IAO. Community-based health insurance programmes and the national health insurance scheme of Nigeria: challenges to uptake and integration. International Journal for Equity in Health 2014 13:20.

13. Obiajulu Nnamuchi. The Nigerian Social Health Insurance System and the challenges of access to health care: an antidote or a white elephant? Electronic copy available at: http://ssrn.com/ abstract $=1138276$

14. Wiesmann D, Jütting J. The Emerging Movement of Community Based Health Insurance in Sub-Saharan Africa: Experiences and Lessons Learned. afrika spectrum. 2000; 35:2.

15. Johannes Jütting. Health Insurance for the poor? Determinants of participation in Community-based Health Insurance Schemes in Rural Senegal. OECD Development Centre Working Paper No. 204. 2003; 2 .

16. Mukangendo $M$, Nzayirambaho $M$, Hitimana $R$, and Yamuragiye A. Factors Contributing to Low Adherence to Community-Based Health Insurance in Rural Nyanza District, Southern Rwanda. Journal of Environmental and Public Health. 2018.Article ID 2624591: 1- 9.

17. Babatunde RO, Oyedeji OA, Omoniwa AE, Adenuga $\mathrm{AH}$. Willingness-To-Pay For Community Based Health Insurance By Farming Households: A Case
Study of Hygeia Community Health Plan In Kwara State, Nigeria. Trakia Journal of Sciences. 2016; 3: 281-286.

18. Kapologwe NA, Kagaruki GB, Kalolo A, Ally M, Shao A, Meshack M, Stoermer M, Briet A, Wiedenmayer $\mathrm{K}$, Hoffman A. Barriers and facilitators to enrollment and re-enrollment into the community health funds/Tiba Kwa Kadi (CHF/TIKA) in Tanzania: a cross-sectional inquiry on the effects of sociodemographic factors and social marketing strategies. BMC Health Services Research. 2017; 17:308.

19. Azuogu BN, Madubueze UC, Alo C, Ogbonnaya LU, Ajayi NA. Level of awareness, and factors associated with willingness to participate in the National Health Insurance Scheme among traders in Abakaliki main market, Ebonyi State, Nigeria. Afr J Med Health Sci 2016; 15:18-23.

20. Hajizadeh $M$ and Nghiem HS Out-of-pocket expenditures for hospital care in Iran: who is at risk of incurring catastrophic payments? Int J Health Care Finance Econ. 2011. 11; (4):267-285.

21. Yusuf HO, Kanma-Okafor OJ, Ladi-Akinyemi TW, Eze UT, Egwuonwu CC, Osibogun AO. Health Insurance Knowledge, Attitude and the Uptake of Community Based Health Insurance Scheme among Residents of a Suburb in Lagos, Nigeria. The West African Journal of Medicine. 2019; 36(2):103-111.

22. Noubiap JJN, Joko WYA, Obama JMN, Bigna JJR. Community-based health insurance knowledge, concern, preferences, and financial planning for health care among informal sector workers in a health district of Douala, Cameroon. Pan African Medical Journal. 2013; 16:17. doi:10.11604/ pamj.2013.16.17.2279.

23. Banwat ME, Agbo HA, Hassan Z, Osagie IA, Ozoilo $\mathrm{JU}$, Ogbonna C. Community Based Health Insurance knowledge and willingness to pay: a survey of a rural community in North Central zone of Nigeria. Jos Journal of Medicine. 2012; 6(1): 54-59. 